\title{
Preparation of Sphaeroplasts from Lactobacillus casei by Growth with Low Concentration of Benzylpenicillin
}

\author{
By K. WATANABE AND S. TAKESUE \\ Institute of Microbiology, Faculty of Pharmaceutical Sciences, \\ Fukuoka University, Fukuoka, Japan
}

(Received 3 April 1973; revised Io May 1973)

A strain of Lactobacillus casei used for the production of a lactic acid beverage is susceptible to phage infections. Calcium ions were required for the formation of PL-I phage-infected bacteria (Watanabe \& Takesue, 1972). Further studies on the role of calcium ions in phage infection required the use of protoplasts or sphaeroplasts of the host bacteria. Early trials using egg-white lysozyme, EDTA or glycine to form sphaeroplasts were unsuccessful. However, a simple procedure to produce sphaeroplasts using a low concentration of benzylpenicillin has been successfully developed and is described here together with information on some factors affecting the stability of the sphaeroplasts.

\section{METHODS}

Lactobacillus casei ATCC 27092 was grown without aeration at $37^{\circ} \mathrm{C}$ in $(\mathrm{w} / \mathrm{v}): \mathrm{I} \cdot 0 \%$ glucose, $\mathrm{I} \cdot 0 \%$ sodium acetate, $\mathrm{I} \cdot 0 \%$ polypeptone (pancreatic digest of casein corresponding to the XVI-USP reagent), $0.3 \%$ beef extract, $0.3 \%$ yeast extract, $0.15 \% \mathrm{CaCl}_{2} \cdot 2 \mathrm{H}_{2} \mathrm{O}$, $0.1 \% \mathrm{NaCl}, 0.02 \% \mathrm{MgSO}_{4} \cdot 7 \mathrm{H}_{2} \mathrm{O}, 0.00 \mathrm{I} \% \mathrm{MnSO}_{4} . \mathrm{H}_{2} \mathrm{O}$ and $0.000 \mathrm{I} \% \mathrm{FeSO}_{4} \cdot 7 \mathrm{H}_{2} \mathrm{O}$ (pH 6.0).

Overnight stationary cultures at $\mathrm{pH} 4.5$ were diluted ten times in freshly prepared growth medium and incubated at $37^{\circ} \mathrm{C}$ for about $4 \mathrm{~h}$. The bacteria in a logarithmic growth phase (turbidity of 0.4 to 0.5 ) were cooled in an ice bath and stored overnight in a refrigerator. The cultures thus obtained were diluted with growth medium to give a turbidity between 0.15 and 0.2 , and a $\mathrm{pH}$ value between 5.5 and 6.0 . Benzylpenicillin was then added to give the desired concentrations.

The turbidity of both the cultures and the sphaeroplast suspensions was measured using a Hitachi EPO-B spectrophotometer with a red filter. The presence of sphaeroplasts was confirmed under an Olympus FH phase-contrast microscope with dark field. Osmotic fragility was assayed by the usual dilution method. The stability of sphaeroplasts was expressed as the relative value of the turbidity of sphaeroplast suspensions.

Potassium benzylpenicillin and the other chemicals were all pure grade purchased from Banyu-Seiyaku Co. and Wako-Junyaku Co. Benzylpenicillin was dissolved in 0.067 Mphosphate buffer of $\mathrm{pH} 7 \cdot 0$ before use. Tris-maleate buffer contained $0.05 \mathrm{M}$-tris (hydroxymethyl)-aminomethane and $0.05 \mathrm{M}$-maleic acid.

\section{RESULTS}

In order to investigate the possibility of benzylpenicillin-induced lysis of Lactobacillus case $i$ and consequent sphaeroplast production, the bacteria in logarithmic growth phase were incubated with benzylpenicillin at concentrations from $0.0 \mathrm{I}$ to $1000 \mu \mathrm{g} / \mathrm{ml}$ at $37^{\circ} \mathrm{C}$ 


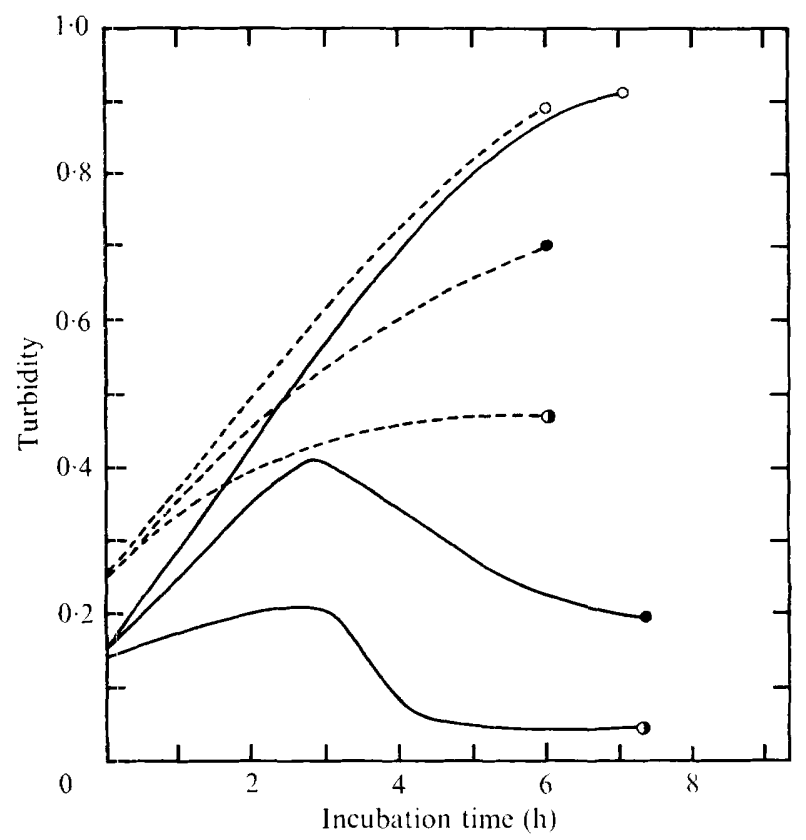

Fig. x. Benzylpenicillin-inhibited growth of cells of Lactobacillus casei resulting in the production of sphaeroplasts. Bacteria collected in the exponential phase were stored at $4{ }^{\circ} \mathrm{C}$ overnight and then incubated with various concentrations of benzylpenicillin in a medium of pH 6.0 at $37^{\circ} \mathrm{C}$. $\mathrm{O}-\mathrm{O}$, No benzylpenicillin (control); - -, $0 \cdot \mathrm{I} \mu \mathrm{g}$ benzylpenicillin $/ \mathrm{ml} ; 0-0, \mathrm{I} \cdot \mathrm{O} \mu \mathrm{g}$ benzylpenicillin/ml.

without aeration and mechanical agitation (Fig. I). Samples were taken at intervals for turbidity measurement and examination by phase-contrast microscopy.

Without benzylpenicillin, turbidity increased promptly without an induction phase, reaching the final turbidity of about 0.9 in $6 \mathrm{~h}$. In the presence of $0 . \mathrm{I} \mu \mathrm{g}$ benzylpenicillin $/ \mathrm{ml}$, the increase in turbidity was slightly suppressed from the beginning of incubation. After passing a maximum turbidity of about 0.4 in $3 \mathrm{~h}$, the turbidity gradually decreased and finally remained at about $0 \cdot 2$. Phase-contrast microscopy showed that the bacteria sampled at this time had all been converted to large bright sphaeroplast forms and that the normal bacillary forms were absent. No addition of sphaeroplast-stabilizing agent such as sucrose was necessary. The sphaeroplasts were collected by centrifugation. They were unstable and burst promptly when diluted with deionized water. Less than $0.1 \%$ of the original viable bacteria were not converted to sphaeroplasts as judged by agar plate counts. Higher concentrations of benzylpenicillin severely inhibited the growth of the bacteria and caused a more rapid lysis. However, the conversion of bacteria to sphaeroplasts was incomplete and various morphological forms including the original rod-shaped ones were present in the lysates. In addition, the sphaeroplasts appeared to be somewhat smaller and shrunken.

Several factors, such as $\mathrm{pH}$ value, composition of medium and the cultural condition of bacteria other than concentration, affected the efficiency of the benzylpenicillin treatment. When calcium chloride was omitted from the growth medium, conversion to the sphaeroplasts were poor. Sphaeroplast production was optimal at $\mathrm{pH}$ values $5 \cdot 5$ to $6 \cdot 0$, lower values than found in most other cases employing penicillin. In accordance with past experience, however, it proved necessary to use young batch cultures as starting material. The bacteria 
which had been cooled in advance for possible synchronization gave a better result. As seen from the dotted lines in Fig. I, in order to ensure the maximum efficiency of benzylpenicillin treatment, the starting turbidity of cultures to which benzylpenicillin was added had to be kept below $0 \cdot 2$.

The sphaeroplasts were collected by centrifugation at I $100 \mathrm{~g}$ for $5 \mathrm{~min}$ and resuspended in $0.05 \mathrm{M}$-tris-maleate buffer, and their stability under various conditions was tested. In a buffer without sucrose, the sphaeroplasts were osmotically fragile and disrupted rapidly. The sphaeroplasts were stabilized by addition of sucrose to the suspending buffer, and at about $20 \%(\mathrm{w} / \mathrm{v})$ sucrose (about $0.6 \mathrm{M}$ ) conditions were optimal. Increase in sucrose concentration beyond $20 \%$ resulted in a decrease in the stability of sphaeroplasts. Glycerol at a concentration of $2 \mathrm{M}$ had about the same stabilizing effect on the sphaeroplasts as $0.6 \mathrm{M}$-sucrose. The presence of magnesium sulphate above $0.02 \mathrm{M}$ in the suspending buffer was necessary to prevent the disruption of sphaeroplasts, though the role of magnesium in this case is not known. The optimal $\mathrm{pH}$ of the suspending buffer for the stability of sphaeroplasts was around $\mathrm{pH} 6.0$ provided that suitable stabilizers were present. As the suspending buffer, phosphate buffer of $0.067 \mathrm{M}$ was as effective as tris-maleate buffer. The sphaeroplasts were found to be most stable in buffer of $\mathrm{pH} 6.0$ containing $20 \%$ sucrose and $0.05 \mathrm{M}$-magnesium sulphate. The temperature of storage, 0,22 or $37^{\circ} \mathrm{C}$, did not affect the stability of sphaeroplasts. Centrifugal treatment, however, strongly affected their stability even in the stabilized buffer, and the turbidity of the sphaeroplast suspensions was greatly reduced by centrifugal treatment even at I $100 \mathrm{~g}$ for $10 \mathrm{~min}$.

\section{CONCLUSION}

The final procedure adopted for sphaeroplast production from Lactobacillus casei ATCC 27092 was as follows. The exponentially growing bacteria were cooled overnight for possible synchronization, and then diluted in growth medium of $\mathrm{pH} 6.0$ to give a turbidity below $0 \cdot 2$. The bacteria were incubated at $37^{\circ} \mathrm{C}$ with benzylpenicillin $(0 \cdot \mathrm{I} \mu \mathrm{g} / \mathrm{ml})$ and without addition of any sphaeroplast-stabilizer. After 5 or $6 \mathrm{~h}$ the rod-shaped forms were all converted to sphaeroplasts as judged by large spherical forms under microscopy and their osmotic fragility. The sphaeroplasts were stable in buffer of $\mathrm{pH} 6.0$ containing $20 \%$ sucrose and $0.05 \mathrm{M}$-magnesium sulphate.

The authors wish to thank Miss S. Sakemi for her technical assistance in part of the experiments.

\section{REFERENCE}

Watanabe, K. \& Takesue, S. (1972). The requirement for calcium in infection with Lactobacillus phage. Journal of General Virology 17, 19-30. 